
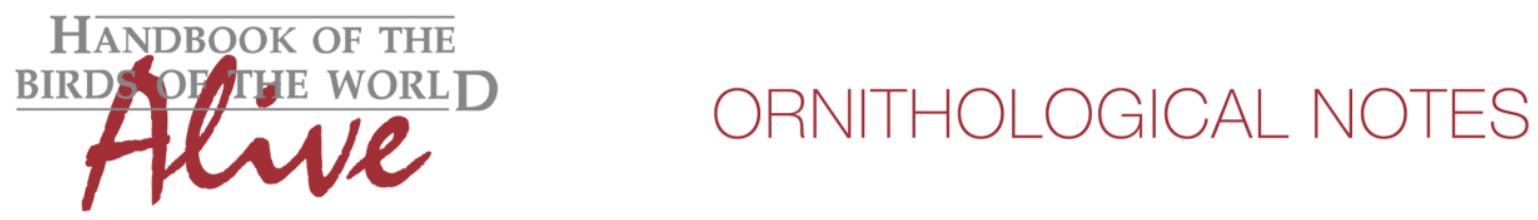

\title{
Notes on the vocalizations of Araripe Manakin (Antilophia bokermanni)
}

Peter Boesman

In the following we briefly analyze voice of Araripe Manakin (Antilophia bokermanni) in comparison with Helmeted Manakin (A. galeata). We also try to quantify the extent of any vocal differences using the criteria proposed by Tobias et al. (2010), as a support for taxonomic review. We have made use of sound recordings available on-line from Xeno Canto $(X C)$.

Song seems to be very similar to Helmeted Manakin A. galeata.

In the original species description (Coelho et al. 1998), vocal differences are given:

'bokermanni shows a remarkable difference in the modulation of the first three notes, which is always increasing in galeata but decreasing in bokermanni.'

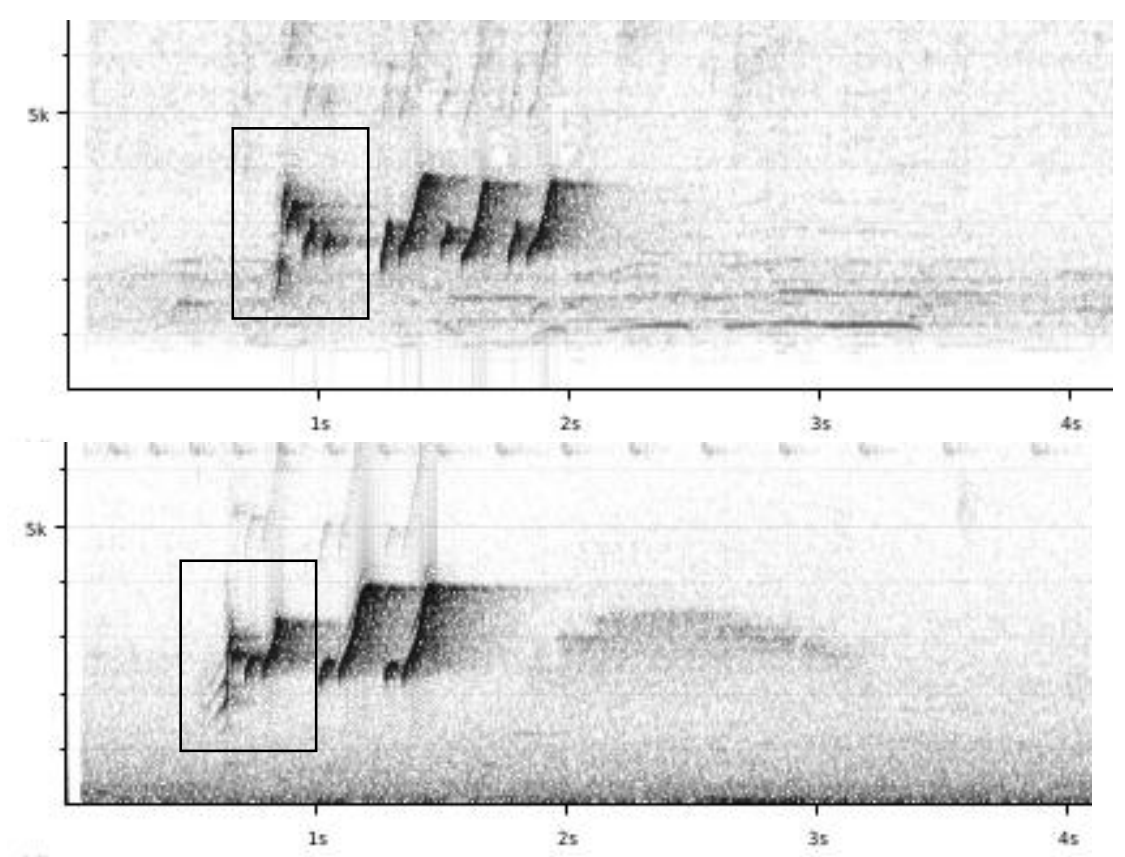

Figure 1: song of $A$. bokermanni (top) and A. galeata (bottom)

From the sonograms (Fig. 1), it can be deducted what is meant: in bokermanni the max. freq of the three introductory notes decreases, while in galeata they increase. It is suggested that this is always the case for galeata.

When checking e.g. the recordings in XC, it is clear that this statement is not correct. The three initial notes of song of galeata can be either rising or falling (Fig. 2), in the latter case (see e.g. XC40001, XC154503, XC173057) indistinguishable from bokermanni A quick check on XC learns that especially birds of the eastern part of its distribution (which are the birds closest to Araripe Manakin) sing with falling notes, although not exclusively At the other hand, I haven't found any song of bokermanni where the first three notes are rising. 

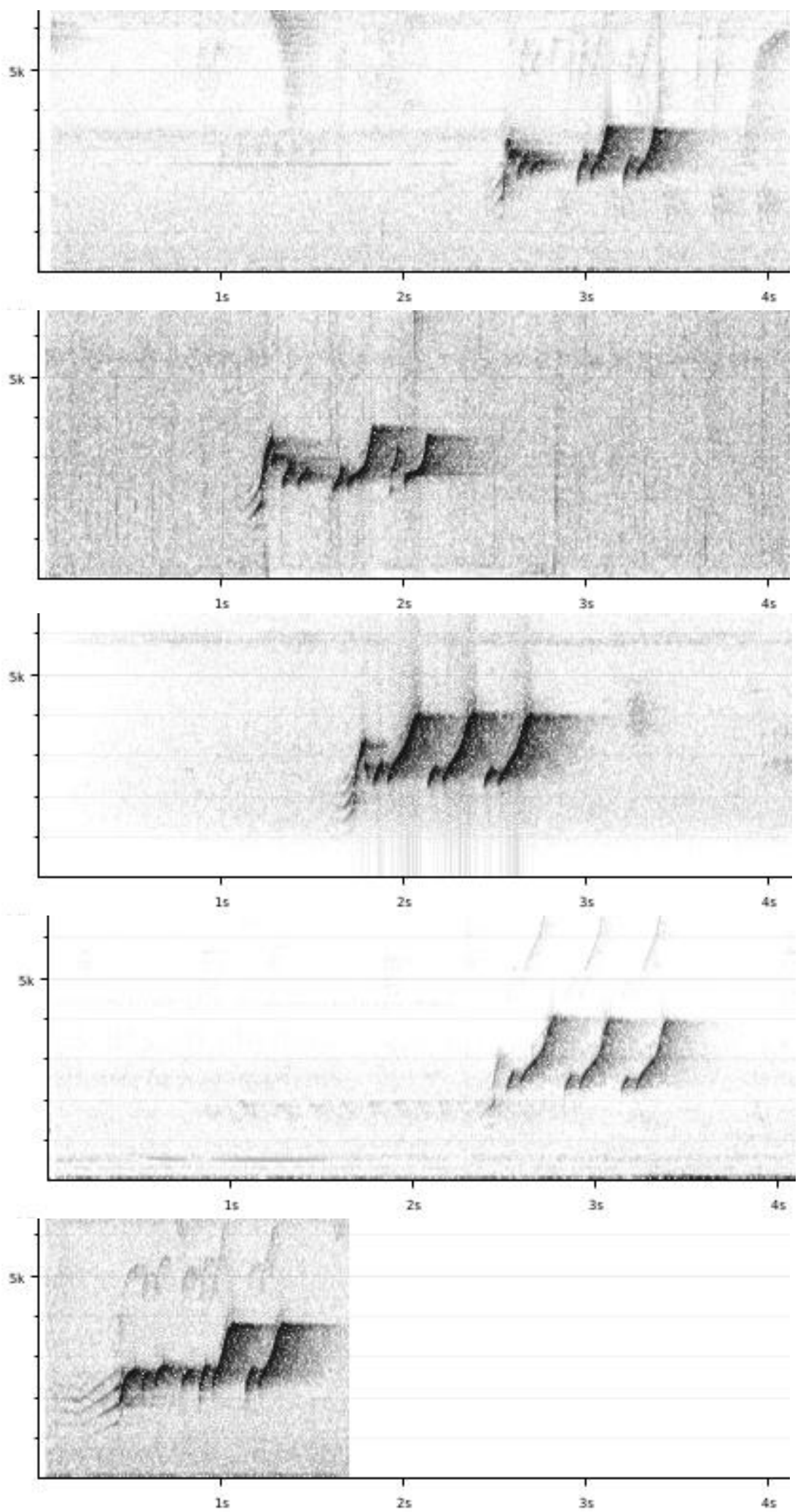

Figure 2: some examples of song of $A$. galeata illustrating the range of variation 

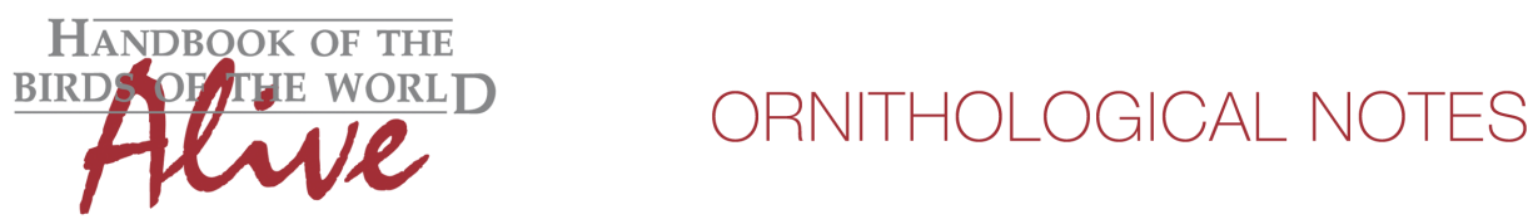

Song of $A$. galeata thus shows more variation, especially in the first three notes of its song. Two 'song types' are frequently heard, one has the first three notes rising (mainly due to the last note being a rising whistle similar to subsequent notes), the other has the three notes falling or at similar pitch. In the latter case, song is indistinguishable from A. bokermanni, which has seemingly only one 'song-type' within its limited geographical range.

We can thus only conclude that song of both species is very similar, and not a truly distinguishing feature, which is not unlike other Manakin groups such e.g. the Manacus group.

This note was finalized on 11th June 2015, using sound recordings available on-line at that moment. We would like to thank in particular the sound recordists who placed their recordings for this species on XC: Ciro Albano, Nick Athanas, Peter Boesman, Miguel Castelino, Allen Chartier, Paul Donahue, Noe Eiterer, Pedro Diniz, Eric DeFonso, Fernando Igor de Godoy, Fernando Favaro, Luiz Fernando Figueiredo, Dan Lane, Gabriel Leite, Hans Matheve, Jeremy Minns, Alvado Prado, Robson Silva and Joseph Tobias.

\section{References}

Coelho, G. \& Silva, W. (1998). A new species of Antilophia (Passeriformes: Pipridae) from Chapada do Araripe, Ceará, Brazil. Ararajuba 6(2): 81-84.

Tobias, J.A., Seddon, N., Spottiswoode, C.N., Pilgrim, J.D., Fishpool, L.D.C. \& Collar, N.J. (2010). Quantitative criteria for species delimitation. Ibis 152(4): 724-746.

\section{Recommended citation}

Boesman, P. (2016). Notes on the vocalizations of Araripe Manakin (Antilophia bokermanni). HBW Alive Ornithological Note 109. In: Handbook of the Birds of the World Alive. Lynx Edicions, Barcelona. (retrieved from http://www.hbw.com/node/932014 on 2 August 2016). 